\title{
Oxidative Stress Following PLGA Nanoparticles Administration to an Animal Model
}

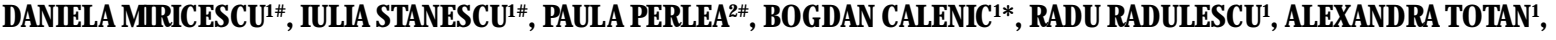 \\ BOGDANA VIRGOLICI ${ }^{1}$, CRISTINA SABLIOV ${ }^{3}$, MARIA GREABU ${ }^{1}$ \\ ${ }^{1}$ University of Medicine and Pharmacy Carol Davila, Faculty of Dental Medicine, Department of Biochemistry, 8 Eroii Sanitari \\ Blvd, 050474, Bucharest, Romania \\ ${ }^{2}$ University of Medicine and Pharmacy Carol Davila, Faculty of Dental Medicine, Department of Endodontics, 19 Calea Plevnei, \\ 010221, Bucharest, Romania \\ ${ }^{3}$ Louisiana State University, College of Engineering, Department of Biological and Agricultural Engineering, Baton Rouge 70803, \\ Louisiana, United States of America
}

In the recent years, engineered nanoparticles (NPS) such as PLGA or poly-lactic-co-glycolic acid, have raised a substantial interest due to their possible medical applications in vaccination, diagnostic imaging procedures, cancer therapy or sustained delivery of drugs. The main aim of the present work is to evaluate key oxidative stress parameters in several organs following NPs administration in an animal model. Our data shows that acute oral administration of PLGA NPs induces a change in the antioxidant status in both rat liver and spleen, but may not induce oxidative stress damage to cell structures such as lipid or protein oxidation.

Keywords: polymeric nanoparticles, oxidative stress, liver, spleen

Nanotechnology is a field of science that has seen a rising interest in the past decade. It deals with particles ranging in size between $0.1 \mathrm{~nm}$ up to $100 \mathrm{~nm}$ called nanomaterials. Nanomaterials can be natural or synthetic and can be classified as carbon based, metal based, polymers or composites [1] and can have a wide variety of shapes and structural organization ranging from nanoparticles to nanotubes, nanofilms or nanofibers. Synthetic nanomaterials are superior to natural ones because they have the advantage of purity and reproducibility [2, 3]. Among them polymeric nanoparticles are between the most researched nanomaterials. Medical applications of nanomaterials range between advanced drug delivery systems [1] to in vivo imaging using nanomaterials as contrast substance carriers [4]. At the same time the use of nanoparticles as advanced drug delivery systems offers numerous advantages such as: high cellular permeability and retention [4], specific tissue targeted drug release [5, 6], slow drug release rate [7-9]. They also reduce drug dosage and protect the drugs from degradation $[1,10]$. The downsides of NPs use as drug carriers are dependency on the drug encapsulation efficiency by the NPs and poor drug loading onto NP [11].

Among NPs, poly lactic-co-glycolic acid (PLGA) is one of the most studied polymers in the field. It is a biodegradable polymer [12] with great potential as a carrier system for drugs, proteins, peptides, DNA and ARN [6, 13]. PLGA is approved by the United States Food \& Drug Administration (US FDA) [6] due to its low system toxicity that comes from the ease of biodegradability by hydrolysis into its two monomers: lactic acid and glycolic acid. These are occurring naturally in the body and are further metabolized in the Krebs cycle. The percentage of its two monomers can vary and it can influence the physical and biological properties of PLGA such as degradation time [4].
It has been shown that PLGA NPs enter the cell via pinocytosis and also through clathrin-mediated endocytosis [14]. They concentrate in the reticuloendothelial system (RES), mainly the liver and the spleen as the body recognizes the PLGA hydrophobic particles as foreign particles [4]. This process most frequently takes place in the non-phagocytic eukaryotic cells, macrophages and dendritic cells [15]. An important factor in NP's cellular distribution is the surface charge. PLGA surface charge can vary from negative to positive or neutral depending if the PLGA particles are surface coated or not. Positive charged NPs localize near the nucleus whereas negative charged particles are found near lysosomes [16]. Also negative charged NPs attract and are removed by phagocytosis more easily by macrophages [17].

One limitation of these NPs is their potential cytotoxicity when used in high concentrations. Thus they can generate oxidative stress (OS) and inflammation due to their small size and possible contamination with metals [18]. The phagocytosis of NPs activates the immune cells and triggers an inflammatory response and a release of inflammatory factors such as cytokines [15]. Cytokines attract more inflammatory cells which in turn, generate more reactive species of oxygen (ROS) from normal cellular processes such as cellular respiration. The internalization of NPs can also generate a release of ROS and subsequent oxidative stress by activating NADPH system [19] followed by the reduction of one electron from $\mathrm{O}_{2}$ to form superoxide anion $\mathrm{O}_{2}$. The accumulation of ROS and the consequent depletion of antioxidants both enzymatic and nonenzymatic, creates the conditions for the onset of OS. Further OS induces structural and functional modifications in nucleic acids, proteins and lipids leading to DNA mutations and cellular damage [20].

One important question when using PLGA NPs in biological systems is related to their concentration and 
exposure time. The present study analyses oxidative stress changes in an animal model exposed to polymeric nanoparticles. Thus the specific aim is to assess key OSrelated molecules, such as glutathione and lipid peroxidation in rats' spleen and liver after acute administration of polymeric NPs.

\section{Experimental part}

PLGA nanoparticles synthesis and characterization

The polymeric nanoparticles of PLGA were prepared by emulsion-solvent evaporation method. Briefly, $400 \mathrm{mg}$ of PLGA or PLGA-FITC were dissolved in $12 \mathrm{~mL}$ ethyl acetate and the organic solution was added to an aqueous solution of $2 \%$ (w/v) PVA ( $120 \mathrm{~mL}$ ). The aqueous phase was saturated with ethyl acetate. The emulsion was mixed in a beaker for $1 \mathrm{~min}$ and homogenized in a microfluidizer M110P apparatus (Microfluidics, Westwood, MA), at $4^{\circ} \mathrm{C}$ and 30,000 psi (three times). Afterwards, the solvent ethyl acetate was evaporated under vacuum $(40 \mathrm{~mm} \mathrm{Hg})$, for 60 min, using R-124 rotary evaporator (Buchi Inc., New Castle, DE). The nanoparticle suspension was dialyzed with $100 \mathrm{kDa}$ cut-off membrane (Spectrum Laboratories, Rancho Dominguez, CA) for two days to remove free PVA. Distilled water was replaced every $8 \mathrm{~h}$, approximately. Finally, the NPs suspensions were combined with trehalose $(1: 1, w / w)$ and lyophilized in Labconco freeze-dryer (Kansas City, MO) at $-80^{\circ} \mathrm{C}$ for $48 \mathrm{~h}$. The polymeric nanoparticle powders were stored at $-20^{\circ} \mathrm{C}$ for further characterization and analysis.

The polymeric nanoparticle size, zeta potential, and polydispersity index (PDI) was determined by Dynamic light scattering (DLS), Zetasizer Nano apparatus (Malvern Instruments, Southborough, MA). The samples were diluted $1: 20(\mathrm{v} / \mathrm{V})$ in HPLC-grade water, and the sample $\mathrm{pH}$ was adjusted to 5 . The temperature was set at $25^{\circ} \mathrm{C}$ and the values of diameter mean, zeta-potential and PDI were determined using a mono-modal distribution.

The morphology of the PLGA and Chi-PLGA NPs was studied by transmission electron microscopy (TEM) using aj EM-1400 system (JEOL, Peabody, MA). The samples were stained with a $2 \%$ uranyl acetate solution, and a droplet of NPs suspension was placed on 400-mesh carbon-coated grids.

The quantification of PVA remaining over PLGA nanoparticles after dialysis was based on colorimetric assay. Briefly, PLGA nanoparticles powder was resuspended in $2 \mathrm{~mL}$ of $0.5 \mathrm{~N} \mathrm{NaOH}$ and the suspension was heated at $60^{\circ} \mathrm{C}$ for $15 \mathrm{~min}$ in an oven. After, with the addition of $0.9 \mathrm{~mL}$ of $1 \mathrm{~N} \mathrm{HCl}$ to neutralize the samples, the final volume of $5 \mathrm{ml}$ was adjusted with distilled water. Subsequent, the addition of $3 \mathrm{~mL}$ of $0.65 \mathrm{M}$ boric acid, 0.5 $\mathrm{mL}$ of a solution $0.05 \mathrm{M} / 0.15 \mathrm{M} \mathrm{I} / \mathrm{KL}$, and $1.5 \mathrm{~mL}$ of distilled water completed a final volume of $10 \mathrm{~mL}$. The samples were incubated at room temperature for $15 \mathrm{~min}$, and measured at $690 \mathrm{~nm}$ with UV-Vis spectrophotometer (Fisher Scientific, Pittsburg, PA). The PVA standard curve was prepared with the same protocol for a PVA concentration range of 2.5 to $60 \mu \mathrm{g} / \mathrm{mL}$.

\section{Animal model}

The animal model involved rats divided in 2 groups as follows: 5 rats were used as control group and 5 rats were administered NPs at a concentration of $50 \mathrm{mg} / \mathrm{kg}$ body weight for $6 \mathrm{~h}$. The mice were purchased from Animal Facility of Carol Davila University of Medicine and Pharmacy, Bucharest, Romania and the experimental procedures were carried outunder Convention 86/609/E.E.C. from November 24,1986 , for the Protection of Vertebrate Animals Used for
Experimental and other Scientific Purposes. The rats were sacrificed at $6 \mathrm{~h}$ after PLGA administration and tissue samples spleen and liver had been collected. The homogenate had been obtained using $\mathrm{KCl} 25 \%$. Glutathione (GSH) and malondialdehyde (MDA) were measured in tissue homogenate.

\section{Oxidative stress markers}

Glutathione (GSH) was detected following the colorimetric reaction, based on the production of a yellow color when 5,5'-dithiobis-(2-nitrobenzoic acid) (DTNB) was added to compounds with sulfhydryl groups. The absorbance was read at $412 \mathrm{~nm}$ and calculation was done using molar extinction coefficient using an adapted method after Beutler $\mathrm{E}$ et al [21].

Malondialdehyde (MDA) is formed by breakdown of lipid hydroxyperoxide. This method is based on the reaction of MDA with thiobarbituric acid (TBA) by heating to produce a complex that can be determined spectrophotometrically [22]. MDA assay: 250uL of homogenate (liver / spleen) were mixed thoroughly with $2.25 \mathrm{~mL}$ working reactive (10 $\mathrm{mL}$ Tricholoroacetic acid (20\%) and $30 \mathrm{~mL}$ TBA (dissolve in $\mathrm{HClO}_{4}$ ). The controls: $250 \mu \mathrm{L}$ of $\mathrm{KCl}$ mixed thoroughly with $2.25 \mathrm{~mL}$ working reactive. The samples and the controls were placed in boiling water for $20 \mathrm{~min}$, cooled to room temperature, centrifuged at $5000 \mathrm{rpm}$ for $10 \mathrm{~min}$ and the absorbance was measured at 532nm.

\section{Statistical Analysis}

Statistical analysis was performed using Stata IC 11 (Stata Corp.2009. Stata release 11. Statistical Software. College Station TX, USA). Students t-test was used to compare and correlate clinical parameters with biochemical biomarkers. Statistical significance was set at a $p$-value of $<0.05$.

\section{Results and discussions}

\section{PLGA nanoparticles characteristics}

PLGA polymeric nanoparticles were spherical in shape (fig. 1) and measured 95 $\pm 2 \mathrm{~nm}$ (PLGA Nps) (table 1). The size distribution was narrow for PLGA Nps (PDI $=0.12)$. PLGA NPs had a negative zeta potential $(-38 \mathrm{mV}$ ) (table $1)$.
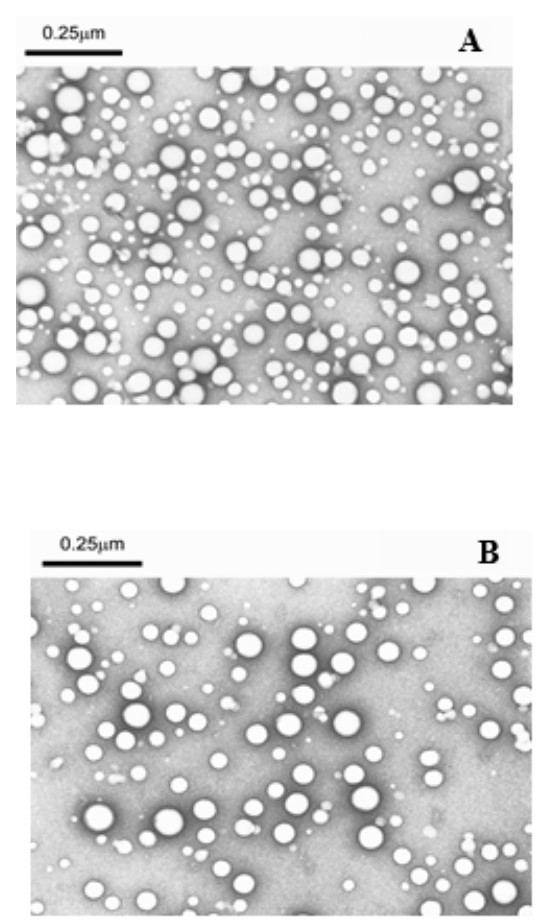

Fig. 1. TEM pictures of PLGA nanoparticles 


\begin{tabular}{|c|c|c|c|c|}
\hline & $\begin{array}{l}\text { Size } \\
\mathrm{nm}\end{array}$ & PI & $\begin{array}{c}\text { Zeta potential } \\
\mathrm{mV}\end{array}$ & $\begin{array}{c}\text { PVA } \\
\%\end{array}$ \\
\hline PLGA & $95 \pm 2$ & $0.11 \pm 0.019$ & $-38 \pm 2$ & $25.8 \pm 0.5$ \\
\hline
\end{tabular}

Table 1

PLGA POLYMERIC NANOPARTICLES CHARACTERISTICS

Note: samples $\mathrm{pH} 5.5$

\section{Oxidative stress markers}

PLGA rat group was sacrificed $6 \mathrm{~h}$ following acute administration of nanoparticles. GSH and MDA levels were analyzed in both spleen and liver from PLGA and control groups as follows: GSH $-0.93 \pm 0.01$ vs. $0.47 \pm 0.01$ for spleen and $0.91 \pm 0.035$ vs. $0.53 \pm 0.3$ for liver in control vs. PLGA group respectively ( $p>0.05$, Student t-test) (fig. 2). As shown GSH levels were decreased in both organs following PLGA exposure in rats treated with nanoparticles when compared with their respective controls. At the same time MDA levels were $0.02 \pm 0.005$ vs. $0.015 \pm 0.004$ for spleen and $0.03 \pm 0.001$ vs. $0.006 \pm 0.001$ for liver in control vs. PLGA group respectively ( $p<0.05$ for spleen and $p>0.05$ for liver Student t-test) (fig. 3). Statistical analysis shows that MDA levels were increased in both organs following PLGA nanoparticles exposure but the increments showed statistical significance only in liver.

\section{GLUTATHIONE}

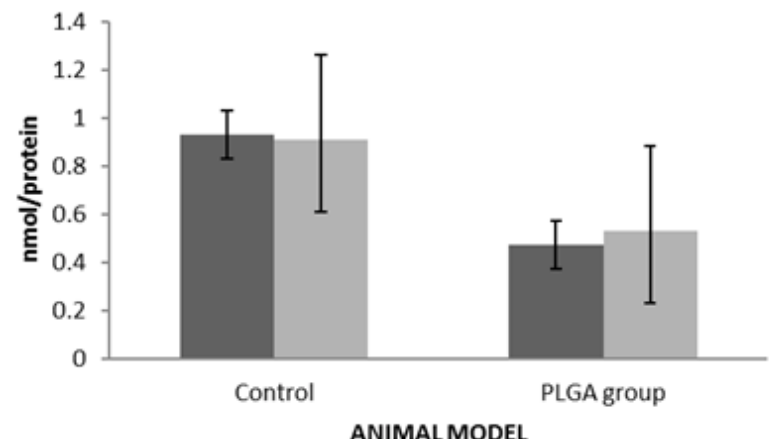

blood vascular system after intravenous injections [24] However oral administration of drugs into the human body present several limitations such as an enzymatic degradation under the acidic environment of the stomach, low intestinal mucosal permeability and rapid clearance of unabsorbed drugs from the GI tract [25]. Intravenous administration of NPs had a very short circulating life span within the body, being rapidly cleared by cells involved in phagocytosis. Previous studies report that NP size, hydrophobicity and charge play a critical role in their uptake by oral administration to mice and rats [26]. To be able to cross the intestinal mucosal barrier of the GI tract, the NPs must have less than $300 \mathrm{~nm}$. Many studies show that the balance between cellular uptake and their cytotoxicity is maintained by finding the best ratios between their properties such as size, concentration and composition.

To test organ NPs bio-distribution, most of the in vivo studies were after administration of a single dose of NPs [27]. Different nanoparticles show different organ preferences. For example a study conducted by Zhang XD concluded that NPs PEG-coated gold with diameters between 5-10 nm will accumulate in liver; particles of 30 $\mathrm{nm}$ will preferentially accumulate in the spleen, and if the particles present diameters of 10-60 nm they have low toxicity in the liver and kidneys [28, 29]. At the same time the highest uptake of PLGA NPs had been detected in the - Spleen animal liver; thus in a study conducted by Semete B and - Liver co-workers it was observed that the major percentage of the particles (40.04\%) were found in the liver; smaller particles seem to accumulate not only in liver but also into the kidney, and in less mounts in the heart and the brain [30].

The potential toxicity after an acute dose administrated

Fig. 2. GSH levels in spleen and liver homogenates following acute PLGA exposure

MALONDIALDEHYDE

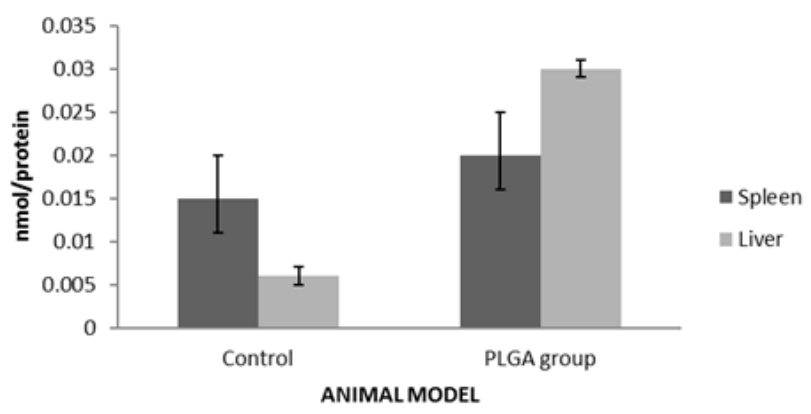

Fig. 3. MDA levels obtained in liver and spleen homogenates following acute PLGA exposure

At the present time, NPs can be used as carriers for a wide variety of biomolecules such as vaccines and drugs into the body using several routes of delivery such as oral or intravenous administration [23]. Oral delivery of drugs using NPs is superior to the delivery of free drugs in terms of bioavialability, biodistribution and residence time. Surface modification of NPs resoles the inconvenient of phagocytosis process and the removal of them from the on rats of PLGA NPs requires detailed evaluation. In the present study 10 Wistar rats were treated with $50 \mathrm{mg} / \mathrm{Kg}$ PLGA NPS, and antioxidant capacity and lipid peroxidation process were evaluated for both liver and spleen. It is well established that glutathione (GSH) is an antioxidant laying paramount roles in the majority of animals, including rats [31] and also in plants. Its main function is to oppose the effect of ROS (exo- or endogenous) and to prevent structural damage to cellular components. In the mammal world GSH has a concentration of around $5 \mathrm{mM}$ and acts as an electron donor. As a biochemical mechanism GSH is converted to glutathione disulfide or GSSG. This ratio between GSH/GSSG is extensively used as a measure of oxidative stress. In the present study we analyzed GSH levels in liver and spleen following acute administration of PLGA nanoparticles. After $6 \mathrm{~h}$ obtained data showed that GSH levels were decreased in the PLGA group versus controls suggesting that the antioxidant defense system reacts to the aggression imposed by the particles. What is important to note is that there is no statistical significance between GSH in the two analyzed groups.

Together with 4-hydroxynonenal (HNE), malondialdehyde (MDA) is the end product of lipid peroxidation process [32]. The present study reports that MDA levels were increased in both hepatic and spleen lysates when compared to their respective controls. However spleen 
MDA levels were notstatistically significantand maintained comparable levels with control MDA. MDA concentration in liver was found to be statistically correlated with controls, pointing to a potential intracellular oxidative stress followed bysubsequent initiation of lipid peroxidation.

\section{Conclusions}

Our research shows that polymeric particles activate the GSH defense system in the spleen, but do not increase significantly the oxidative stress levels. Regarding MDA, the results of the present study indicate that PLGA NPS may increase its levels in liver when a high dose is administered for short term. However, further research on oral delivery of PLGA NPs using chronic doses is needed in order to fully understand particle behavior in vivo.

Acknowledgements:This work was supported by a grant from the Romanian National Authority for Scientific Research and Innovation, CNCS - UEFISCDI, projectnumber PN-II-RU-TE-2014-4-1879.D.M. would like to thank for the Young Scientist Grant 2014-2016 received from University of Medicine and Pharmacy Carol Davila, Bucharest, Romania.

\section{References}

1.LU, J.M., WANG, X., MARIN-MULLER, C., WANG, H., LIN, P.H., YAO, Q., CHEN, C., Expert Rev Mol Diagn, 9, no. 4, 2009, p. 325-341. 2.ASTETE, C.E., SABLIOV, C.M., J Biomater Sci Polym Ed, 17, no. 3, 2006, p. 247-289.

3.VIRLAN, M.J.R., MIRICESCU, D., TOTAN, A., GREABU, M., TANASE, C., SABLIOV, C.M., CARUNTU, C., CALENIC, B., J. Chem., 2015, 2015. 4.DANHIER, F., ANSORENA, E., SILVA, J.M., COCO, R., LE BRETON, A., PREAT, V., J Control Release, 161, no. 2, 2012, p. 505-522.

5.DANHIER, F., FERON, O., PREAT, V., J Control Release, 148, no. 2, 2010, p. 135-146.

6.MAKADIA, H.K., SIEGEL, S.J., Polymers (Basel), 3, no. 3, 2011, p. 1377-1397.

7.AMOOZGAR, Z., WANG, L., BRANDSTOETTER, T., WALLIS, S.S., WILSON, E.M., GOLDBERG, M.S., Biomacromolecules, 15, no. 11, 2014, p. 4187-4194

8.PANYAM, J. LABHASETWAR, V., Adv Drug Deliv Rev, 55, no. 3, 2003, p. 329-347.

9.VIRLAN, M.J.R., MIRICESCU, D., RADULESCU, R., SABLIOV, C.M., TOTAN, A., CALENIC, B., GREABU, M., Molecules, 21, no. 2, 2016, E207.

10.MUDSHINGE, S.R., DEORE, A.B., PATIL, S., BHALGAT, C.M., Saudi Pharm J, 19, no. 3, 2011, p. 129-141.
11.KUMARI, A., YADAV, S.K., YADAV, S.C., Colloids Surf B Biointerfaces, 75, no. 1, 2010, p. 1-18.

12.RUSU, L. C., PIRTE, A., BORTUN, C. M., HOINOIU, B., PODARIU, A. C., ARDELEAN, L., NEGRUTIU, M.L., SINESCU, C., PLES, H., Rev. Chim. (Bucharest), 66, no. 2, 2015, p. 233-235.

13.J AIN, R.A., Biomaterials, 21, no. 23, 2000, p. 2475-2490,

14.SAHAY, G., ALAKHOVA, D.Y., KABANOV, A.V., J Control Release, 145, no. 3, 2010, p. 182-195.

15.NICOLETE, R., DOS SANTOS, D.F., FACCIOLI, L.H., Int Immunopharmacol, 11, no. 10, 2011, p.1557-1563.

16.YUE, Z.G., WEI, W., LV, P.P., YUE, H., WANG, L.Y., SU, Z.G., MA, G.H., Biomacromolecules, 12, no. 7, 2011, p. 2440-2446.

17.STEVENSON, R., HUEBER, A.J., HUTTON, A., MCINNES, I.B., GRAHAM, D., ScientificWorldj ournal, 11, 2011, p. 1300-1312.

18.SINGH, N., MANSHIAN, B., JENKINS, G.J., GRIFFITHS, S.M., WILLIAMS, P.M., MAFFEIS, T.G., WRIGHT, C. ., DOAK, S.H., Biomaterials, 30, no. 23-24, 2009, p. 3891-3914.

19.FADEEL, B. KAGAN, V.E., Redox Rep, 8, no. 3, 2003, p. 143-150.

20.PISOSCHI, A.M., POP, A., Eur J Med Chem, 97, 2015, p. 55-74.

21.BEUTLER, E., DURON, O., KELLY, B.M., J. Lab. Clin. Med., 61, 1963, p. 882-888.

22.ESTERBAUER, H. CHEESEMAN, K.H., Method Enzymol, 186, 1990, p. 407-421.

23.PRIDGEN, E. M., FRANK, A., OMID C., Clin Gastro and Hepat. 10, 2014, p. 1605-1610.

24.MAHAPATRO, A., SINGH, D.K., J Nanobiotechnology, 9, 2011.

25.THOMPSON, C.J ., TETLEY, L., CHENG, W., Int J Pharm, 383, no. 1, 2010, p. 216-227.

26.MOHANRAJ, V., CHEN, Y., Trop J Pharm Res, 5, no. 1, 2006, p. 561573.

27.NAVARRO, S.M., DARENSBOURG, C., CROSS, L., STOUT, R., COULON, D., ASTETE, C.E., MORGAN, T., SABLIOV, C.M., Ther Deliv, 5, no. 11, 2014, p. 1191-1201.

28.ZHANG, X.-D., WU, D., SHEN, X., LIU, P.-X., YANG, N., ZHAO, B., ZHANG, H., SUN, Y.-M., ZHANG, L.-A., FAN, F.-Y., IntJ Nanomedicine, 6, 2011, p. 2071-2081.

29.SIMON, L.C., SABLIOV, C.M., Drug Metab Rev, 46, no. 2, 2014, p.128-141.

30.SEMETE, B., BOOYSEN, L., LEMMER, Y., KALOMBO, L., KATATA, L., VERSCHOOR, J., SWAI, H.S., Nanomedicine, 6, no. 5, 2010, p. 662671.

31.ALEXA, A.I., CANTEMIR, A., CIOBICA, A., GARDIKIOTIS, I., ANTIOCH, I., HONCERIU, C., ZAMFIR, C.L., POROCH, V., Rev. Chim. (Bucharest), 68, no. 1, 2017, p. 90-93

32.SCROBOTA, I., ALB, C., CALNICEANU, H., BACIUT, G., NEAGOE, I. B., ONISEI, D., POPOVICI, A.R., BUZATU, R., BOLFA, P., Rev. Chim.(Bucharest), 66, no. 9, 2015, p. 1467-1470.

Manuscript received: 22.12.2016 